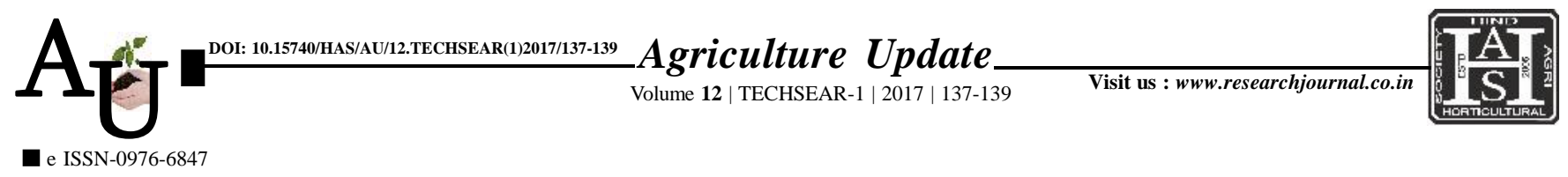

\title{
Research Article: Resistance to borer complex infestation in sugarcane clones
}

\author{
- V. BASKARAN, M. SHANMUGANATHAN, R. NAGESWARI AND R. \\ CHANDRASEKARAN
}

Article Chronicle :

Received :

05.07.2017;

Accepted :

22.07.2017

\section{Key Words :}

Sugarcane, Early

shoot borer, Chilo

infuscatellus,

Internode borer,

Chilo

sacchariphagus

indicus

Author for correspondence :

\section{BASKARAN}

Sugarcane Research

Station (T.N.A.U.)

Sirugamani,

TIRUCHIRAPPALLI (T.N.)

INDIA

Email:varadharajbhaskaran@

gmail.co.in

See end of the article for

authors' affiliations
SUMMARY : Field trials were conducted in Randomized Block Design with three replications at Sugarcane Research Station, Tamil Nadu Agricultural University, Sirugamani Tiruchirappalli, Tamil $\mathrm{Nadu}$, India. The infestation levels in clones of sugarcane were assessed and graded. Sugarcane clones were categorized based on the degree of resistance/susceptibility according to resistance scale. The first set of field experiments revealed that early shoot borer infestation and per cent of dead heart was minimum in Si 2011-355 (4.17 \%) and maximum in Si 2011-349, Si 2011-415, Si 2011-598 and Si 2011$631(8.70 \%)$. The internode borer damage was recorded minimum in Si 2011-359 (8.0\%) and maximum (37.5\%) in Si 2011-371. The clone Si 2011-359 recorded higher cane yield of $131.40 \mathrm{t} / \mathrm{ha}$ and minimum 93.67 t/ha in Si 2011-631 In the second set of experiment among the twenty six clones, Si 2012-329 (6.00 $\%$ ) and $\mathrm{Si} 2012-38$ (39.40\%) recorded the minimum and maximum dead heart damage due to early shoot borer, respectively. The internode borer damage was 3.80 per cent in Si 2012-329 which was the minimum among the clones of sugarcane.

How to cite this article : Baskaran, V., Shanmuganathan, M., Nageswari, R. and Chandrasekaran, R. (2017). Resistance to borer complex infestation in sugarcane clones. Agric. Update, 12(TECHSEAR-1) : 137-139; DOI: 10.15740/HAS/AU/12.TECHSEAR(1)2017/137-139. 